\title{
CHAPTER SIX
}

\section{Designing and Playing Peer-Produced ARGs in the Primary Classroom: \\ Supporting Literacies through Play}

\author{
Angela Colvert
}

In recent years, a number of studies have explored the ways in which alternate reality gameplay supports children's learning in classroom settings (Carroll and Cameron, 2003; Niemeyer et al., 2009; Connolly et al., 2011). However, there has been little investigation into the educational benefits of engaging students in alternate reality game design (Chess and Booth, 2014), and pupils designing ARGs in mainstream school settings appears to be a rare occurrence (Colvert, 2009; 2015). If pupils are supported to become ARG designers what will they learn? What will we learn from them? How might ARG design and play shape and transform pedagogical approaches in formal education? This chapter will present a design-based account of the planning, making, and playing 
stages of an ARG from the perspective of a group of young 10- and 11-year-old designers who were supported by their class teacher to create an ARG for a class of 9 and 10 year olds in the same school. The findings of this study extend current conceptions of ARG design and will be of interest to those who wish to view the educational potential of ARGs from a fresh perspective. Drawing on analysis of the texts produced prior to and during play, interviews with the designers, and teacher observations, the chapter highlights how the designers identified their own key design principles and in doing so successfully tackled issues and challenges relating to fictionality, authenticity, and agency.

\section{Aims and methodology of the research project}

The research project described in this chapter was undertaken in a large London primary school by a teacher-researcher who set out to investigate how engaging in the peer production of an ARG would support children's literacies in a classroom context. In this study three dimensions of literacies were in focus: cultural, critical, and operational (Green, 1988; Beavis and Green, 2012). Operational dimensions of literacies related to the technical skills and understanding needed to manipulate and appropriate resources, cultural dimensions related to the way the children drew on their knowledge of discourses to shape meanings and the critical dimensions related to the way in which they reflected on and managed power relations. The three sub-research questions which shaped the investigations were:

- How are the critical dimensions of the designers' literacies demonstrated as they manage the rule systems of the ARG?

- How are the cultural dimensions of the designers' literacies demonstrated as they appropriate modes and media during ARG authorship?

- How are the operational dimensions of the designers' literacies demonstrated as they shape the networked structures of the ARG? 
The act of authorship is a process of communication which involves shaping discourse through the design, production, distribution (Kress and van Leeuwen, 2001) and interpretation (Burn and Durran, 2007) of messages. Therefore, in order to answer the research questions, the analysis of data needed to extend the teacher-researcher's understanding of the acts of meaning-making undertaken by the designers at each of the stages of ARG authorship: data was gathered throughout the planning, making, and playing process and included semi-structured interviews held at the end of the project, texts which formed part of the ARG produced prior to and during play, and planning documents. In order to better understand the social purpose of the texts which the designers produced, the teacher-researcher undertook thematic coding of interview data, which provided insights into the designers' "interests" (Kress, 2010) and intentions. The thematic codes which emerged from this analysis then provided foci which informed the multimodal analysis of the textual components of the ARG.

\section{Overview of the Mighty Fizz Chilla ARG}

The ARG discussed in this chapter was based on The Mighty Fizz Chilla, a novel by Philip Ridley (2002): a story in which a mysterious Captain asks a young boy for help in catching the monster which has ruined his life. The game-design project which formed the basis of the research positioned the teacher-researcher's class of 10- and 11 -year-olds (the designers) as expert game designers and storytellers. They were challenged to 'bring the story to life' and create a game for a class of 9- and 10-year-olds (the players) who would need to find the "Mighty Fizz Chilla" (or "MFC"), the monster at the heart of Ridley's story, before it reached the school. The teacher-researcher explained to the designers that in creating the game they would need to develop the narrative, consider the rules that would shape play, and create puzzles and problems for players to solve. The theme of the quest, a hunt for a monster, which was central to the novel, would also be key to the game, the difference being, of course, that in the novel the quest is narrated, whereas in the ARG the quest would be partially narrated by, and partially enacted by, the players (who had not read the novel). The designers understood that, through game design, they were to create a playful and exciting 
experience for both the players and themselves. In setting this brief, the teacher-researcher hoped that the designers would be prompted to present players with an "embedded narrative" (Salen and Zimmerman, 2004) and a "digital pretext" (Carroll and Cameron, 2003; Carroll and Cameron, 2009; Anderson et al., 2009) that would support the dramatic participation of the players and the creation of an "emergent narrative" (Salen and Zimmerman, 2004) during play.

\section{Planning}

After the class had discussed their initial responses to the brief, the teacher-researcher asked them to reflect on how they would set about constructing "a trail of clues" which would help the players to identify, locate, and catch the Mighty Fizz Chilla. The teacherresearcher prompted them to reflect on where the players might want to search for information about the creature and what forms of evidence they might seek. Drawing on their knowledge of the "new media landscape" (Kress, 2010), the designers decided to present visual, auditory, and written evidence to players, and that the clues should be dispersed across a range of media: websites (including message boards) film (such as webcam diary entries and CCTV footage) artifacts (such as books and maps) and live dramatic action (events occurring in the classroom and playground such as the school secretary delivering parcels to the players' classroom). The designers also decided that the setting of Ocean Estate featured in Ridley's novel should be given an online identity in the form of a community website. They suggested that this website could provide the players with access to a range of webpages and a variety of text types that they would produce, including newspages, tourist information sites, and the personal webpages of characters. They also suggested that the website should contain links to message boards which could support their communication with players.

In the next planning meeting, the designers were divided into five working groups, each of which was responsible for communicating and designing in role as one of the novel's characters: Mr. Chimera, Dee Dee Six, The Captain, Cressida, and Milo Kick. Each group was asked to consider how their character could help the players complete the quest and prompted to reflect on what information 
their characters could reveal. The class decided that only the Captain's group and Mr. Chimera's group would reveal information about the appearance of the creature as, in the novel, only these characters had first-hand experience of the monster. The designers also decided that the group representing Milo in the game should primarily support the players to locate the creature but that the Captain's group might also provide information about its whereabouts (in Ridley's novel, the character Milo is a young boy of thirteen, enlisted by the Captain to help him track down the MFC). In contrast to the other characters in the novel, Cressida and Dee Dee Six know nothing about the MFC and so the designers decided that they should not reveal any information about the creature to players during the game. Instead the class decided that their groups would offer support to players as they tried to catch the creature.

To further support the designers, the teacher-researcher constructed a planning aid to help the class to visualize the "web of clues" they were constructing. Each of the flies on the web represented a clue, a piece of information, which would reveal something about the identity and whereabouts of the creature or suggest actions the player might take to catch it. The spiders represented the players who would need to collate, interpret, and act on the information in order to complete the quest. A large version of this diagram was used during subsequent planning meetings and as clues were suggested by each group these were recorded on the images of the flies.

\section{Making}

Each group decided to make websites, film footage, and artifacts which would reveal key information needed to complete the quest and help players to identify, locate, and catch the MFC. The process of making these texts was an iterative one which was informed by weekly whole-class planning meetings in which the groups updated each other, and the teacher-researcher, about their progress and sought advice about their developing ideas. These regular meetings supported the teacher-researcher in planning the resources needed for the following week, but more importantly, allowed for the cross pollination of ideas. These regular discussions often led to collaboration between groups, particularly as they began to shape the challenges they would set players. 


\section{Identifying the MFC}

One of the first challenges the designers set for players was to identify the MFC. The players would need to find multiple references to the creature and construct an image of the monster. To support the players in this, the Captain's group included references to the MFC on his personal webpages. These webpages were intended to support players to connect the references to "beasts," "creatures," and "monsters" found in other texts in the game with the name of the creature they were looking for. Both the Captain's group and Mr. Chimera's group also wrote online news articles which included witness statements alluding to partial sightings of the creature, intended to give the players hints as to the MFCs strange appearance: it had the face of a shark, stripes like a tiger, wings like a bird, and a horn like a unicorn. Significantly, both groups decided to withhold images of the MFC until the players were nearing completion of the quest as they felt this would help to sustain and extend the players' imaginative engagements and investigations. In this way, the designers left conceptual gaps (Iser, 1980) in the narrative for the players to fill. Although they intended to give players access to the websites from day one of gameplay, artifacts which contained visual images of the creature such as a "wanted" poster (see Figure 6.1) and a book about "creatures of the deep" (see Figure 6.2) would be revealed later.

\section{Locating the MFC}

Another of the challenges the designers set for the players was to locate the MFC. The players would need to obtain maps and plot the creature's progress in order to ascertain the route by which it would arrive at their school. To this end, Milo's group created an "ancient" map of the Thames (see Figure 6.3) which highlighted the whereabouts and dates of sightings. They also created a map of the sewers which led from the Thames (the nearest river to the school) to the drains in the school playground. In order to alert players to the existence of the maps and prompt them to ask for items, Milo's group created a weblog in which Milo recounted finding a strange map on the beach. In shaping this challenge Milo's group enlisted the help of the Captain's group to create additional maps, asking them to record a weblog in role as the Captain, reporting that his maps had been stolen. 


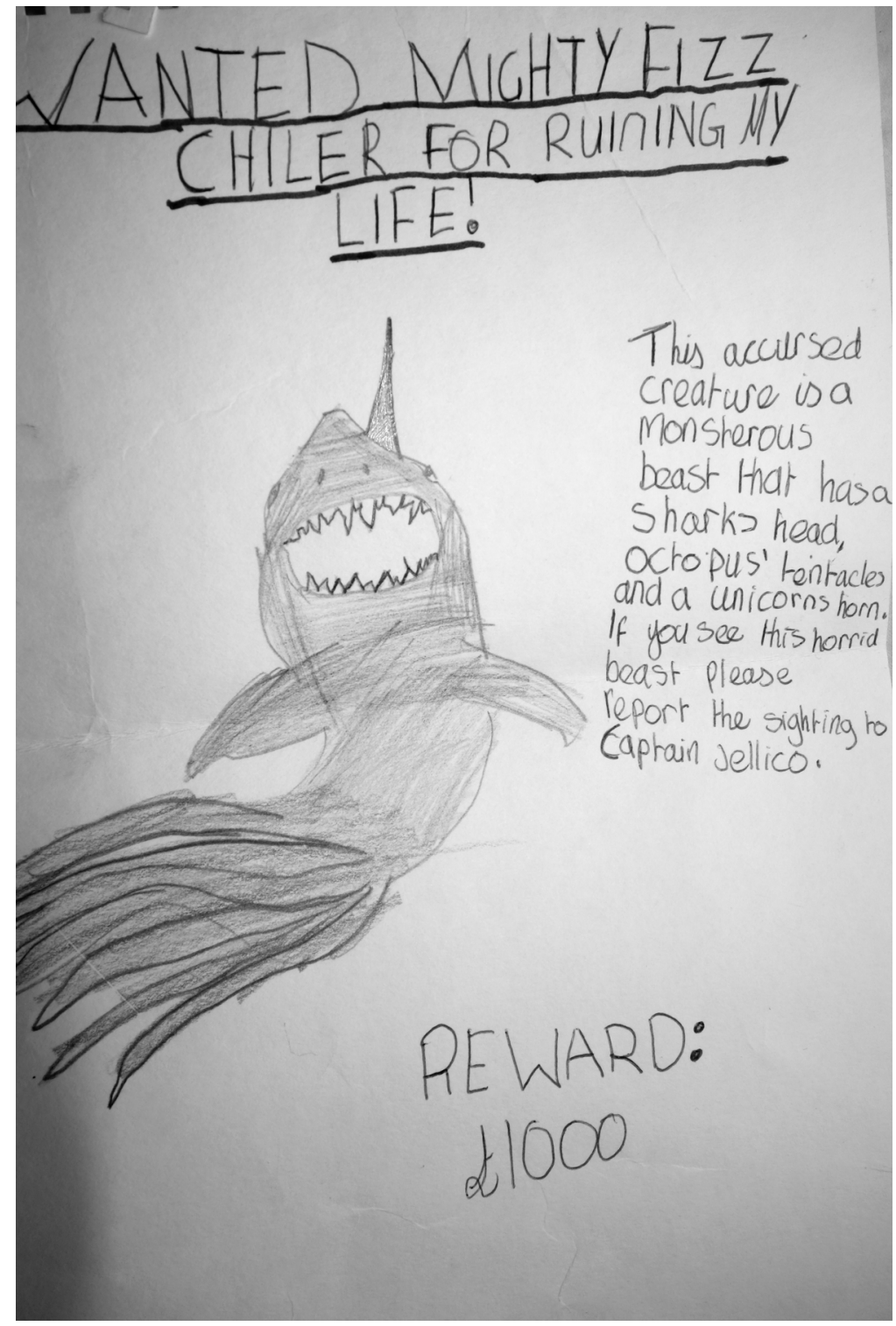

FIGURE 6.1 Wanted poster created by the Captain's group. 


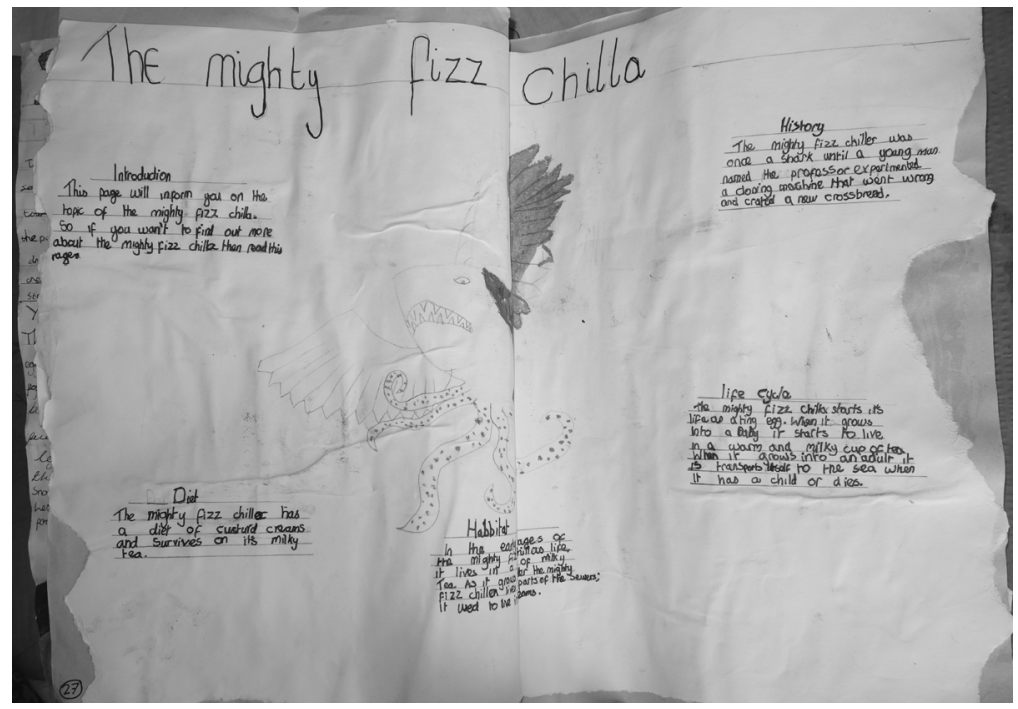

FIGURE 6.2 MFC page in the Creatures of the Deep book collated by Mr. Chimera's group.

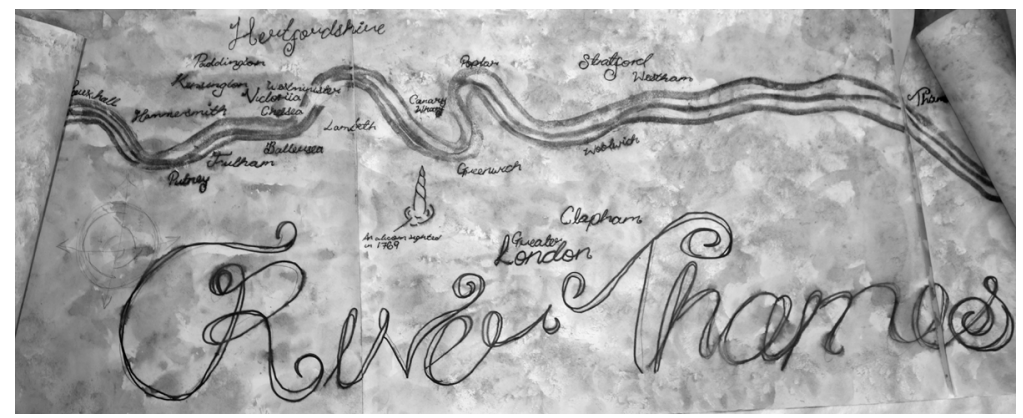

FIGURE 6.3 Map of the Thames created by Milo's group.

\section{Catching the MFC}

Once the players had worked out that the monster would arrive at the school via the sewer system and located the possible point of entry into the playground-one of the drains-they would need to decide the best action to take. Would the players choose to tame or kill the creature? Dee Dee Six's group decided that their character, a 
scientist, would provide support to players in creating magic formulae. They produced personal websites in role which provided information, via one of the links on the homepage, about the potions she could create. They also created weblogs in which she discussed her frustration about a spilt potion which now prevented her from catching or taming a beast. These texts were intended to prompt the players to ask her for help in creating a potion. The group planned to deliver a book of "Mythical Recipes" to players when asked, and they enlisted the help of the class in writing potions for this book. Cressida's group collaborated with Dee Dee Six's in shaping this challenge, proposing that the ingredients needed should be delivered to players in a locked box which could only be opened by cracking a code on a rock they would produce. Cressida's group produced the coded rock and Dee Dee Six's created the cipher needed to crack it by writing some of the words in the potion book in the same code.

\section{Playing}

During the week that it took to play the ARG, the teacher-researcher spent each morning in class with the players observing and prompting their engagement with the game. Each afternoon the teacher-researcher returned to her own class and supported the designers in reflecting on the next steps they needed to take, providing them with access to message boards so they could communicate with players. The game began when the teacherresearcher shared an email she had received from residents explaining that a beast on the loose had been causing havoc in Ocean Estate, and that now the creature appeared to be heading to their school. The email, which was a warning and a call for help, had been written by the young designers and the teacher followed a script she had been given by the designers when introducing the challenge. At the end of the email was a link to the Ocean Estate website and, after accepting the challenge with great enthusiasm, the players explored the multiple webpages in search for information. On day two the players began to post their findings and emerging theories and plans on the message boards, and started to ask the characters of Ocean Estate for help. On day three the designers made the link to the webcams live and, after watching these, the players asked the characters to send them artifacts featured in the film footage they had seen. On day four, the artifacts arrived in the post. There was 
great excitement among the players as they unwrapped the parcels and examined the contents. On day five the players collated all the information they had found, made the potion needed to catch the creature, poured it on the MFCs favorite food, and placed the bait by a drain in the school playground. After the weekend, on day six, the players discovered that the bait had gone and found an egg in its place. After much debate about what should be done with the egg, the players incubated it only to discover that, after one playtime, the egg had hatched and the monster escaped! However, inside the egg was a riddle which, once solved, would lead the players to a meeting with the designers. In this meeting, which signaled the end of the game, the designers congratulated players and presented them with individually designed certificates. They also shared "behind the scenes" information about how the game was produced.

\section{Identifying key design principles}

At the end of the game, semi-structured interviews were held with each group of designers, during which they were asked to reflect on their experiences of the project. Transcripts of these interviews were thematically coded in order to identify key authorial concerns and three broad themes were identified: agency, fictionality, and authenticity. The theme of agency related to the ways in which rules were managed, fictionality was related to the ways in which the fiction of the Mighty Fizz Chilla was developed during the game, and the theme of authenticity was related to how the experience of the game was conceptualized as "play" by the designers and players. Intersecting these themes, three categories also emerged: managing modality (relating to broader themes of fictionality and authenticity), constructing coherence (related to both fictionality and agency), and directing action (relating to agency and authenticity). Once identified, these categories were explored further through analysis of the texts produced before and during play in order to discover more about how engaging with these design principles supported the designers' literacies.

\section{Managing modality}

The category of "managing modality" subsumed codes such as "believability" and "reality/fantasy" and related to broader concerns 
with the fictionality of the MFC and the authenticity of play. The term modality is drawn from the "social theory of the real" (Kress and van Leeuwen, 1996) where modality "serves to create an imaginary 'we'. It says, as it were, these are the things 'we' consider true, and these are the things 'we' distance ourselves from" (1996:155). The ambiguity of the reality status of ARGs, the blurring of the boundaries between fact and fiction, has long been considered to be a defining characteristic of the genre. There is some research which suggests that this aesthetic design principle, which sees many ARG designers and players adhering to the mantra "This is Not a Game" (Szulborski, 2005; McGonigal, 2003), may have educational benefits for young people playing ARGs in class: increasing motivation (Connolly et al., 2011) developing children's critical thinking (Bonsignore et al., 2012) and supporting role-play and the participants' adoption of attitudinal roles (Carroll and Cameron, 2003). However, there has been little investigation into how negotiating and shaping the "reality status" of an ARG with and for their peers might support children's literacies. Examining how the designers managed modality during the peer production of this ARG reveals insights into the cultural dimensions of literacies required in such an endeavor.

The texts produced prior to and during play contained "modality cues" intended to situate the reader in relation to the text and to guide players' attitude towards the messages. These modality cues signaled the "reality status" of the texts and shaped the relationship between game designers and players, supporting the audiences' interpretation of the proposed "truthfulness" of representations. For example, linguistic modality markers, words like "might," "should," "could," and "can," indicated the different levels of certainty and assurance attributed to the utterance (Halliday and Hasan, 1985); "I will" has a higher modality, and makes a stronger truth claim than "I might" and "it could be a monster" has a lower modality, makes a weaker truth claim than "it is a monster" (Davies, 1997). Images also shaped the modality claims made by the game. For example, the designers sometimes decided to include naturalistic photographic images as, in some contexts, such images are often considered to be more "realistic" (Kress and van Leeuwen, 2006) according to a "naturalistic," everyday perspective. However, the texts presented by the designers were intended to cue the players to interpret their "fantasy" status of the texts. 
Before play, the designers reflected on how they would support players to accept and engage imaginatively with the fictional premise of the game. In one planning meeting a designer expressed her concern that the players might find it hard to invest the effort needed to "believe" in the fiction of the MFC:

I just think the monster is erm the actual monster [the Mighty Fizz Chilla] isn't really not believable type of monster I mean [...] I mean I [...] think that we could have bel[ieved] I think they could believe like a dragon or something but not a half shark half squid type thing cause I think it's quite an hard thing to work with.

Since the appearance of the MFC was so unusual, in order to support players to "perform belief" (McGonigal, 2003) the designers decided to adapt the fiction of the monster and make it appear more "plausible," by framing it within more traditional fantasy conventions. They also considered ways to make the existence of the MFC more "possible," by contextualizing the fiction within a science fiction narrative.

In order to encourage the perception of the MFC as a plausible monster, the designers in Mr. Chimera's group invited the players to draw on their cultural knowledge of mythical creatures. So, for example, the introductory paragraph on Mr. Chimera's website referenced a range of fantasy animals and contained an explicit invitation to engage with the fiction:

My name is Mr. Chimera this home page is for magic people. People witch [sic] believe in magic things and mythical creatures such As pixies, baby krakens, unicorns and many others. Read on and feel the magic tingle up your spine...

Here the designers cue the player's interpretation of the "reality status" of the site by using linguistic markers which signal the fantasy modality proposed by the game; the word magic is repeated three times and nouns like pixies, unicorns, and krakens are prefaced by the adjective mythical. By addressing the players directly, the designers situate them as participants in an imaginary world and suggest that if they explore the site and "read on," then they should accept the fiction in order to get maximum pleasure from 
the experience and feel their spine "tingle." Similarly, another of Mr. Chimera's websites invited players to "contact" the character to find out more about "wondrous" and "fantasticle" creatures. Play would not be possible without the actions of players and their mock acceptance of the "magic." Images on these webpages were also intended to cue the players to recognize and accept the fantasy modality of the game, depicting familiar monster "types" such as dragons and merpeople, as well as creatures they had invented such as the "Tropical Piranhadon" and the "Flame-Headed Thunder Snake." Common to all of the images on these sites were the nonspecific backgrounds to the pictures, which impacted on the modality status of images: Kress and van Leeuwen assert that:

By being 'decontextualised', shown in a void, represented participants become generic, a 'typical example', rather than particular, and connected with a particular location and specific moment in time.

KRESS and VAN LEEUWEN, 2006: 161

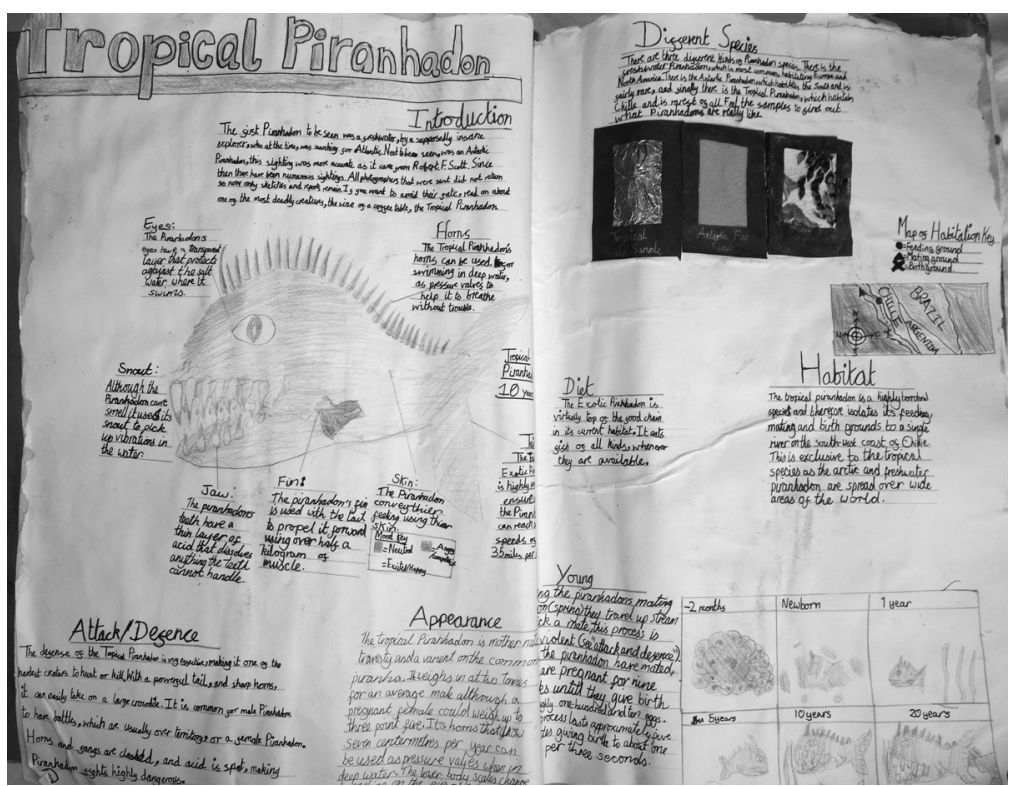

FIGURE 6.4 Tropical Piranhadon. 
In this instance, each of the images is intended to be indicative of a type of creature. Mythological creatures are "types" which are not necessarily rooted in a particular time or place and therefore although the images are not all "naturalistic" the lack of background could actually be seen to strengthen the fantasy modality claims of the game.

Before play the designers in Dee Dee Six's group also made the monster seem more possible by constructing a science fiction narrative about cloning to explain its existence. Part of this narrative was revealed in a newspaper article, headlined "Fearsome Formulas," which reported that: "On Tuesday this week we discovered a severe breakthrough in evolutionary science. Scientists have been working on a formula which will mutate animals to adapt to a much harsher environment." The article went on to explain that:

We think the government are trying to hush up a severe accident. We believe that some of the so-called 'god sent formula's' have leaked in to the Thames. If we are correct we may have mutated fish swimming around.

Kress and van Leeuwen (2006) explain that "in the dominant discourses of 'our society', 'belief' has lower modality than 'knowledge', 'dream' lower modality than reality, and 'religion' lower modality than 'science." However, the tentative tenor of this reportage actually serves to heighten the truth claims made by this article from the "naturalistic" perspective of "everyday reality," as the reticence to state absolute truths is typical of serious news reports. Drawing on scientific discourse in this way can also be seen to lower, or temper, the fantasy modality claims made by the representations of more "fantastical" creatures.

During play, modality claims were negotiated in online exchanges between designers and players. For example players often indicated their mock acceptance of magic through the use of winking emoticons at the end of their messages. In one such interaction, a player asked Dee Dee Six's character a question about a potion and the designers responded in role (see Figure 6.5).

Here, the player uses the word "potion" as a modality cue, indicating and accepting the fantasy modality of the game. A winking emoticon is also used at the end of the question, apparently 


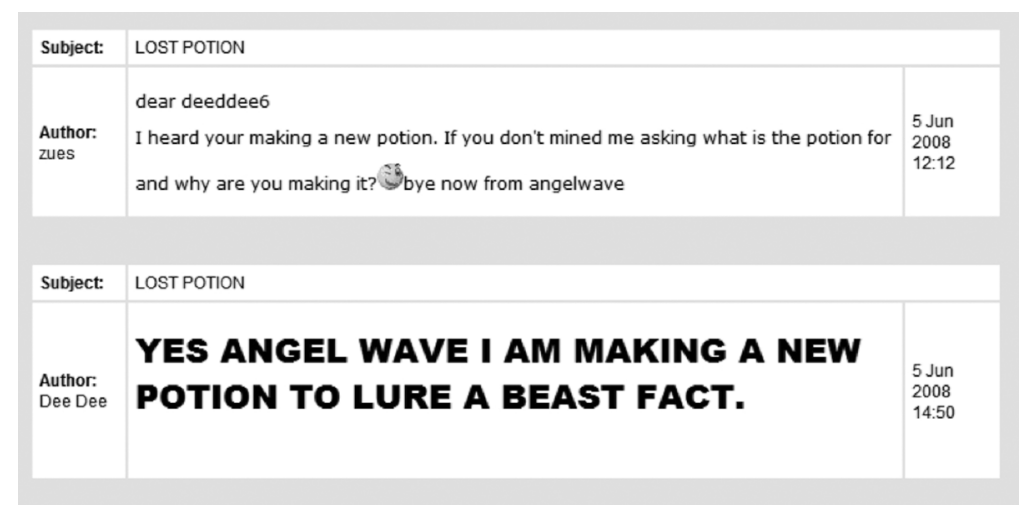

FIGURE 6.5

signaling its playful nature. The response from Dee Dee Six's group is consistent with the character as represented on her website. The word "fact" is used to emphasize the validity and certainty of the short statement. Additionally, the choice of font, combined with the fact that message is typed in bold and in capitals, serves to add to the tone of certainty and assertiveness, characteristics of the character's scientific "world view" that are communicated in other areas of the game, such as on her personal. Although the designers select the word "beast," which has a lower fantasy modality than "monster," the word "potion" clearly signals the fantasy modality claims being made. Occasionally the players contested modality claims, for example by pointing out inconsistencies they perceived in representations of characters. However, in the few instances in which the players' expressed incredulity, the messages also simultaneously communicated the desire to play along by asking characters to provide further information or send objects by post (Colvert, 2009).

Authoring transmedia texts such as ARGs poses particular challenges for young designers as they involve shaping complex tapestries of modality claims and counter claims. However, in this study the designers rose to the challenge-managing the modality of the game with their peers in sophisticated ways and supporting the players' ability to "judge both the modality markers of the text and their significance" (Hodge and Kress, 1988: 130) during play. This communication with peers in order to perpetuate play 
demonstrated a deep understanding of the cultural significance of both the modes and media used in the ARG, and reframed the cultural dimensions of the designers' literacies as they considered how to construct an authentic fiction with and for their peers.

\section{Co-constructing coherence}

In coding the interview data, the broad category of "co-constructing coherence" subsumed codes such as "working out/interpreting clues," "correcting player's interpretations," and "incorporating players' ideas." "Coherence" here refers to the "impression of textual unity which the reader interprets and recognizes based on the linguistic and contextual cues she receives" (Halliday and Hasan, 1985: 72). ARG design involves creating a tapestry of texts and a key concern for adult designers is often how best to utilize the resources at their disposal so that each part contributes to the whole (Jenkins, 2006). However, having produced a network of texts, it is only during play that designers are able to assess whether players are perceiving a coherent narrative: "when a reader perceives a group of sentences or utterances to form meaning in relation to each other, these are considered to be a text" (Halliday and Hasan, 1985: 72) and although the designers of ARGs can guide players' meaning-making, they cannot accurately predict how texts will be interpreted or in what order they will be accessed (or indeed if some will be accessed at all!). Investigating the designers' co-construction of coherence during play revealed insights into the operational literacies required to sustain game play through the construction of complex networked texts.

In order to better understand how the designers created a coherent fiction in collaboration with players, the teacher-researcher analyzed the structure of the texts they produced, drawing on theories of cohesion outlined in the work of Halliday and Hasan $(1976 ; 1985)$ and Lemke (2002). In particular focus was the way in which the designers distributed references to the MFC prior to play in order to support the players in making conceptual links, and to guide players' interpretations. Halliday and Hasan's work is primarily concerned with grammatical and lexical cohesion in linguistic texts, and therefore shaped the analysis of the written and spoken words in the game. Using Lemke's (2002) examination of hypermodality supported the analysis of the cohesive ties within the hypertext of the websites. 
Prior to play all the designers distributed references to the MFC across modes, media, across the texts made by other groups and over time (Colvert, 2013). Many of the texts in the game did not explicitly name the monster on the loose, and instead referred to the MFC as a "beast" or "strange creature" or "monster." To help players to recognize these terms as references to the MFC, and therefore recognize the significance of the clues, the Captain's group included multiple references to it within and across the Captain's personal webpages:

Welcome to my Home page!!!! Strictly no Mighty Fizz Chillas allowed!!!! Trespassers will be harpooned! Curse Ye, Ye horrid beast, Curse Ye!!!!!

Sorry, I've gone into another of my rages again. Anyway, this website will tell ye all about my adventures across the seven seas, and everything ye need to know about the cursed creature!!!! Ye know what I'm talking about, right? Ye don't know?! It's the Mighty Fizz Chilla!!!! Arghhh!!!!!

In this short passage the designers use the phrases "horrid beast" and "cursed creature" as synonyms for the MFC, creating cohesive ties between the references and cuing the players to make conceptual links between these terms. On another of the Captain's websites the designers introduce the acronym for the Mighty Fizz Chilla: "AS THE WORLD KNOWS IM HUNTING THE, THE ... THE MFC STAND FOR MIGHTY FIZZ CHILLA.” It was important that the players understood and recognized the synonyms used to refer to the MFC as this would help them to identify important information in texts which did not explicitly name the MFC.

During play it became clear that the players had misinterpreted some of the references to the MFC, and that this had resulted in them "discovering" multiple monsters. One player explained that they had discovered that were two monsters (" $2 \mathrm{~m}$ ”) on the loose: "hi we have a lots more we no a abot of are $2 \mathrm{~m}$." Other players proposed that there may be even more creatures on the loose and that Milo might be one of them: "Sorry to tell you this but they're might be two monsters or even three! [...] I think that he [Milo] is the second monster fizzy wasp and that might help Although during play the designers often accepted unexpected interpretations if they would not adversely 
affect gameplay, in this instance they decided that it would be necessary to correct the players as they felt that including additional monsters in the game would make it too complex and difficult to manage.

Cressida's group wrote in role on the message boards in order to clarify that the phrase "fizzy wasps" used in the game was metaphoric.

In these interactions the designers shaped and strengthened cohesive ties between references to the MFC to reduce ambiguity and in doing so asserted their authority over the possible interpretations of texts in an attempt to influence the players' meaning-making. This ability to shape and manage the coherence of the ARG demonstrated the sophisticated operational dimensions of the designers' literacies, as they mapped references to the creature across a complex network of texts both prior to and during play.

\section{Directing actions}

The category of "directing action" included codes relating to "guiding players' actions," "correcting players' actions," "multiple possibilities," and the "importance of [the] feedback loop." Negotiating the power dynamic between puppeteers and players is a key concern for ARG designers and requires careful management, particularly as the actions of players can often be unpredictable (McGonigal, 2007). In AR Gs designed for classroom use, teachers and researchers generally take responsibility for guiding players and deciding when to intervene. However, a number of researchers have begun to reflect more on how democratic approaches to ARG design and play might be achieved in the classroom, and more autonomy granted to student players (Niemeyer et al., 2009). Investigating the designers' management of the rule systems of the game, and their facilitation and guidance of the "consequential actions" (Laurel, 1993) of players revealed insights into the critical dimensions of literacies involved.

The category of "directing actions" was investigated by undertaking discourse analysis of the message boards, as it was through online dialogue that the designers prompted and rewarded players' actions. Although critical discourse analysis is primarily concerned with analyzing spoken and written language (Fairclough, 2003), the approach is compatible with multimodal analysis. In the analysis of the message boards, both the written text, and multimodal 
features such as font and color of words chosen, and the emoticons used were attended to. There were multiple "speakers" on the message boards, but these were grouped into two sets: players and designers. The designers would post messages for the players either to elicit or reveal information. Alternatively, they would respond to players' calls for action or attempt to prompt players to act. Fairclough usefully distinguishes between

'knowledge exchange', where the focus is on exchange of information, eliciting and giving information, making claims, stating facts, and so forth; and 'activity exchange', where the focus is on activity, on people doing things or getting others to do things.

Both types of exchange were analyzed in order to better understand the ways in which the agency of players was managed by the designers. This analysis involved investigating the impact of demands and offers constructed by the multimodal texts (Kress and van Leeuwen. 1996) on both the agency of players and designers, and on the authenticity of the quest; in this the function and effect of visual compositions and of linguistic statements (factual, predictive, hypothetical, and evaluative) and questions, were examined.

Prior to play the designers modeled action and knowledge exchanges on message boards in order to prompt players to initiate action.

Later in gameplay Milo's group tried to prompt the players to ask for a map (in order to keep track of the creature's location). To this end they produced some webcam footage with the intention of encouraging the players to initiate an action exchange. However, again, the designers did not make explicit demands for the players to act; instead they used evaluative statements and gestures to persuade the players to ask for objects. Fairclough suggests that "noting the implicit value-content of factual statements [helps] to make a link between the apparent orientation to knowledgeexchange and [...] a deeper orientation to activity-exchange" (Fairclough, 2003: 112). In the webcam footage the designer performing in role as Milo begins by stating "I was on the clifftop and I found this amazing map," emphasizing the word amazing by 
lengthening its pronunciation. In addition to linguistic cues, the character of Milo employs gaze and gestures to draw the players' attention to the items. Milo's evaluative statements are combined with demands, both linguistic and visual, on two occasions: the phrases "Look at it. Innit. Cool innit." and later "Looks cool, come on" are combined with the complimentary action of holding the map briefly up to the camera giving players just a glimpse of it. The designer performing in role uses tone and exclamations to indicate her excitement at possessing the object, thus suggesting the artifact's value. Gazing at the map, Milo says "WOW" breathlessly before continuing, "Cool innit." Through attaching values to the map featured in the webcam footage, the designers are encouraging the players to ask for it.

During play the designers entered into written exchanges with the players on the message boards, and in this way were able to give feedback on the players' progress in the game, both positive and negative. A positive response involved "accepting an offer, carrying out a command, acknowledging a statement and answering a question" (Halliday, 2004:108), whereas a negative or "discretionary" (Halliday, 2004: 108) response, might involve rejection of an offer of goods-and-services, refusal of a demand for action, a contradiction of information offered, or a refusal to provide information. The designers gave positive feedback on the message boards which let players know they were on the "right" track and were asking the "right" questions. If the players demanded actions that would further the quest then the designers responded positively with a reply that might reasonably be expected by the players. For example, if the players asked the characters to send items that were needed in the quest then the designers would agree to send them. This can be seen in the following online exchange between the designers, writing in role as Milo, and a player:

Subject: Capt maps!!!

Author: pig Hey Milo we got your video on the computer. We want the maps that you got because it could lead to where the moster will go and attack next. Please please can you give us those maps. We the maps to caputure the monster before it attcks again.

Author: Anonymous I will send it to onyx and he will send it to you ok 
In this sequence the player has initiated an action exchange and asked the "correct" question, asking for the map as the designers had hoped he would. This "expected response" (Halliday, 2004: 108) from players was in turn responded to by the designers with two statements indicating that the action would take place and the map be sent. If the players did not demand the items needed to complete the quest then the designers continued to prompt them to do so, and if the players asked for items that the designers were not expecting them to ask for, the designers might refuse to send them.

It seems significant that the designers' demands are disguised: they aim to tempt the players to act rather than demanding that they do so. The agency of players, the possibilities for consequential action are implied rather than stated, and the rules governing playthat is the need to ask for items-are not made explicit. These communicative choices have implications for the ludic structure and authenticity of the game. In this ARG the designers presented the game as a space of possibility (Salen and Zimmerman, 2004) more akin to the experience of the free play of paidia (Caillois, 1961) than the rule-bound ludus (Caillois, 1961), despite the ludic structure which needed to be adhered to. In doing so the designers demonstrated the critical dimensions of their literacies, carefully and purposefully managing the power relations between themselves as original designers of the game and the players in order to perpetuate play.

\section{Pedagogical and theoretical implications}

This chapter has begun to outline pedagogical implications of peerto-peer ARG authorship in a classroom setting by highlighting ways in which the process reframed the literacies of a group of young designers. However, the findings of this study have broader implications and demonstrate that ARG authorship in schools can offer a way of reframing curriculum provision too. This study also makes a theoretical contribution in shaping a hybrid model of ARG authorship which maps the key authorial concerns expressed by the young designers onto the cultural, operational, and critical literacies demonstrated in the process. 


\section{Reframing cultural dimensions of literacies}

ARG authorship not only prompted the designers to reframe their own cultural literacies but also provided a useful pedagogical frame for supporting the cultural dimensions of children's literacies in a classroom setting. Burnett et al. suggest that "an empowering literacy education involves a recognition of the affective, embodied and material dimensions of meaning making" and that it should emphasize "that meaning-making is inflected by what we feel, what has just happened and who we are with, as well as how we are positioned by those people and things around us" (Burnett et al., 2014: 163). Designing the ARG with and for their peers heightened the designers' awareness of the affective nature of meaning-making, particularly when they discovered that players were not responding in ways they had expected them to. The feedback loop in the ARGs enabled designers and players to communicate with each other, supported the negotiation of modality claims and meanings, and brought to the fore the socially-situated nature of communication. This reframing of literacy practices through ARG design is particularly pertinent for educational settings in which cultural dimensions of literacies are often sidelined in favor of a more cognitive stance, in which literacy is viewed as a skill to be learned, and understandings of fixed meanings are constructed and demonstrated by the individual rather than collectively.

\section{Reframing operational dimensions of literacies}

ARG authorship also provides opportunities for reframing operational dimensions of literacies in formal education, foregrounding and supporting multiple authorship practices rather than the individual practices often valued in school settings. The process brings to the fore the provisionality of text making, characteristic of new authorship practices (Williams, 2014) rather than the "fixity of the types of 'finished' or 'polished' texts [...] produced within set time periods in specific lessons" (Burnett et al., 2014: 160): the texts in the ARG were shaped and reshaped in an iterative process of communication and, through the use of forums, both players and designers collaborated in developing the texts which supported play. Providing opportunities to construct 
coherence when creating and interpreting transmedia texts in collaboration with others is important if we are to support young people in becoming active contributors and participants in shaping the new media landscape. Burnet et al. have suggested that "empowering literacy education values collaboration in text making and is emancipatory in the way it facilitates access to other's texts and ideas" arguing that "institutions need to find ways of valuing collaborative work" as "working on texts together [and] embedding links and sources from multiple sites are all skills that the young are likely to need in their future lives if not in school" (Burnett et al., 2014: 163). This study required the designers to shape the operational dimensions of their literacies together as they created cohesive chains across work produced by different groups and individuals, often embedding hyperlinks on their own webpages to the webpages of others or referring to texts produced by other groups in their own textual productions. This is not a technical ability that was recognized in the formal assessments of school but was important to the project and to their understanding of how transmedia texts function and shape the experiences of readers/players.

\section{Reframing critical dimensions of literacies}

In relation to reframing approaches to supporting critical dimensions of literacies in schools, ARG authorship provides a context through which power relations can be explored in a playful context. Burnett et al. suggest that an empowering literacy education involves "exploring how you position yourself and how you are positioned by others through texts" and education needs:

to support critical engagement to help children and young people understand how young people understand how texts and related materials position readers and players. Given that so much of life is played out online, this critical dimension needs to go beyond the text analysis so often associated with critical literacy to include a focus on how individuals can and want to be presented online, the kinds of communities they participate in and how these relate to 'broader social and textual networks'

BURNETT and MERCHANT, 2011:50, BURNETT et al., 2014: 164 
The process of ARG authorship outlined in this chapter provided a fictional frame in which designers adopted hybrid identities, performed online, representing themselves as fictional characters in the game whilst simultaneously adopting the role of real game designers who were responsible for guiding the community of players. ARG authorship thereby prompted the designers to explore the ways texts can prompt and direct the actions of others and in that can involve subtle, hidden, assertions of authority from participants. ARG authorship thereby reframed the critical dimensions of the designers' literacies as, given the iterative nature of game design and play, the process required that they address issues relating to power, and carefully manage their own authority as the original designers.

\section{Reframing play as a 3D literacy practice}

Although this chapter has primarily focused on how the designers' literacies were framed by play, I argue that it is also useful to consider the findings of this study from the inverse perspective. How was play framed by the children's literacies? Play in this study was conceptualized as a process of meaning-making which involved managing modality, constructing coherence, and directing action. This study suggests that not only can literacies be considered to have operational, cultural, and critical dimensions but play can too: during ARG authorship literacies are framed by play and play is framed by literacies. One of the contributions of this study is a new hybrid model of ARG authorship which maps three dimensions of literacies (Beavis and Green, 2012) onto the key design principles explored by the young designers during peer-to-peer play. This model of ludic authorship can be represented in a Venn diagram.

This hybrid theoretical model of ARG authorship offers a fresh perspective on the interconnected relationship between literacies and play. Wohlwend argues that we should "redefine play as a literacy, a key component of 'new basics'” (Dyson, 2006) [...] in twenty-first century literacies' and suggests that this might go some way to "empowering teachers to reclaim curricular space in their classrooms" (Wohlwend, 2011: 127). It is hoped that this threedimensional approach to conceptualizing play as literacy, might also go some way to supporting teachers, and game designers, to 


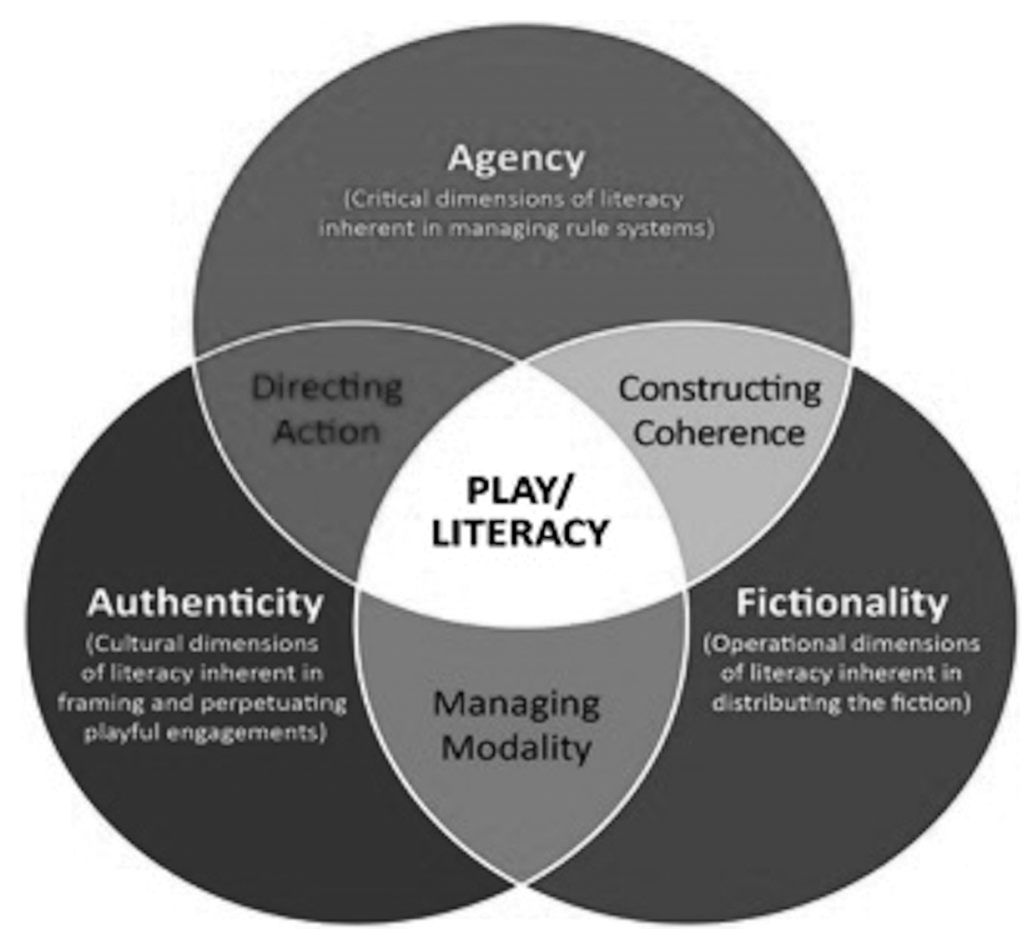

FIGURE 6.6 Key authorial concerns, and associated literacies, demonstrated during ARG Authorship.

plan opportunities for peer-to-peer game design in classrooms and also articulate the rationale for such a move.

\section{References}

Anderson, Michael, John Carroll and David Cameron. 2009. Drama education with Digital Technology. London; New York: Continuum International Pub. Group.

Beavis, Catherine, and Bill Green, B. 2012. "The 3D model in action: a review." In Literacy in 3D: an Integrated Perspective in Theory and Practice, edited by Bill Green and Catherine Beavis, 39-60. Camberwell, Victoria (Australia): ACER Press.

Bonsignore, Elizabeth, Kari Kraus, Amanda Visconti, Derek Hansen, Ann Fraistat, and Allison Druin. 2012. "Game design for promoting 
counterfactual thinking." In CHI '12: Proceedings of the SIGCHI Conference on Human Factors in Computing Systems, 2079-82.

Burn, Andrew, and James Durran. 2007. Media Literacy in Schools: Practice, Production, and Progression. London: Chapman.

Burnett, Cathy, and Guy Merchant. 2011. "Is there space for critical literacy in the context of social media?" English teaching practice and Critique vol.10, no.1: 41-57.

Burnett, Cathy, Julia Davies, Guy Merchant, and Jennifer Rowsell, eds. 2014. New Literacies Around the Globe: Policy and Pedagogy. Abingdon, Oxon: Routledge.

Caillois, Roger. 1961. Man, Play and Games. Translated by Meyer Barash. New York: The Free Press of Glencoe.

Carroll, John, and David Cameron. 2003. "To the Spice Islands: Interactive process drama," 5th International Digital Arts \& Culture Conference. Melbourne: RMIT.

Carrol, John and David Cameron. 2009. "Drama, digital pretext and social media in Research in Drama Education." The Journal of Applied Theatre and Preformance, 14, 295-312.

Chess, Shira, and Paul Booth. 2014. "Lessons down a rabbit hole: Alternate Reality Gaming in the classroom." New Media and Society 16(6): 1002-17

Coiro, Julie, Michele Knobel, Colin Lankshear, and Donald Leu. 2008. "Central issues in New Literacies and New Literacies Research." In Handbook of Research on New Literacies, edited by Colin Lankshear, Michele Knobel, Donald Leu, and Julie Coiro, 1-22. New York: Laurence Erlbaum.

Colvert, Angela. 2009. "Peer Puppeteers: Alternate Reality Gaming in Primary School Settings." Paper presented at DiGRA, Breaking New Ground: Innovation in Games, Play, Practice and Theory, Brunel University. www.digra.org/dl/db/09287.19018.pdf

Colvert, Angela. 2013. "What is the MFC?” In Virtual Literacies: Interactive Spaces for Children and Young People, edited by Guy Merchant, Julia Gillen, Jackie Marsh and Julia Davies, 105-25. New York: Routledge.

Colvert, Angela. 2015. Ludic Authorship: Reframing Literacies through Peer-to-Peer Alternate Reality Game Design in the Primary Classroom. Unpublished PhD thesis. Institute of Education: University College London.

Connolly Thomas, Mark Stansfield, and Thomas Hainey. 2011. “An alternate reality game for language learning: ARGuing for multilingual motivation." Computers and Education 57(1): 1389-1415.

Davies, Maire Messenger. 1997. Fake, Fact, and Fantasy: Children's Interpretations of Television Reality. Mahwah, N.J.: Erlbaum. 
Dyson, Anne Haas. 2006. “On saying it right (write): 'fix-its' in the foundations of learning to write" Research in the Teaching of English, 41: 8-44.

Fairclough, Norman. 2003. Analysing Discourse: Textual Analysis for Social Research. London: Routledge.

Green, Bill. 1988. "Subject-specific literacy and school learning: a focus on writing." Australian Journal of Education 32(2): 156-79.

Halliday, Michael Alexander Kirkwood. 2004. An Introduction to Functional Grammar. London: Routledge.

Halliday, M.A.K, and Ruqaiya Hasan. 1976. Cohesion in English. London: Longman.

Halliday, M.A.K, and Ruqaiya Hasan. 1985. Language, Context, and Text. Geelong, Victoria (Australia): Deakin University Press.

Hodge, Robert, and Gunther Kress. 1988. Social Semiotics. London: Polity Press.

Iser, Wolfgang. 1980. The Act of Reading: A Theory of Aesthetic Response. Baltimore: Johns Hopkins University Press.

Jenkins, Henry. 2006. Convergence culture: Where old and new media collide. New York: New York University Press.

Jenkins, Henry. 2006a. "Game Set Interview: Henry Jenkins on the Responsibility of games.” http://www.gamesetwatch.com/2006/06/ gamesetinterview_henry_jenkins.php

Jenkins, Henry. 2006b. Confronting the Challenges of Participatory Culture: Media Education for the 21st Century. MacArthur Foundation Reports on Digital Media and Learning.

Kress, Gunther. 2010. Multi-Modality: A Social Semiotic Approach to Contemporary Communication. London: Routledge.

Kress, Gunther, and Theo van Leeuwen. 1996. Reading Images: The Grammar of Visual Design. London: Routledge.

Kress, Gunther, and Theo van Leeuwen. 2001. Multimodal Discourse: The modes and media of contemporary communication. London: Edward Arnold.

Laurel, Brenda. 1993. Computers as Theatre. London: Addison-Wesley.

Lemke, J.L. 2002. "Travels in hypermodality." Visual Communication 1(3): 299-325.

McGonigal, Jane. 2003. “A Real Little Game: The Performance of Belief in Pervasive Play.” Level Up Conference Proceedings: DiGRA 2003. Utrecht: University of Utrecht. www.digra.org/dl/ db/05097.11067.pdf

McGonigal, Jane. 2007. “The Puppet Master Problem: Design for Real-World, Mission Based Gaming.” In Second Person: Role Playing and Story in Games and Playable Media, edited by Pat Harrigan and Noah Wardrip-Fruin. Cambridge, MA: MIT Press. 
Niemeyer, Greg, Antero Garcia, and Reza Naima. 2009. "Black cloud: patterns towards da future." Proceedings of the 17th ACM International Conference on Multimedia, 1073-82.

Ridley, Philip. 1992. Krindlekrax. London: Penguin.

Ridley, Philip. 2002. Mighty Fizz Chilla. London: Penguin.

Salen, Katie, and Eric Zimmerman. 2004. Rules of Play: Game Design Fundamentals. Cambridge, MA: MIT Press.

Sutton-Smith, Brian. 2001. The Ambiguity of Play. Cambridge, MA: Harvard University Press.

Van Leeuwen, Theo. 1999. Speech, Music, Sound. London: Macmillan. Williams, Bronwyn. 2014. "Mobility, Authorship, and Students' (Im) material Engagement with Digital Media and Popular Culture.” In New Literacies around the Globe: Policy and Pedagogy, edited by Cathy Burnett, Julia Davies, Guy Merchant, and Jennifer Rowsell, 140-54. Abingdon, Oxon: Routledge Press.

Wohlwend, Karen. 2011. Playing Their Way into Literacies: Reading, Writing, and Belonging in the Early Childhood Classroom. London and New York: Teachers College Press. 


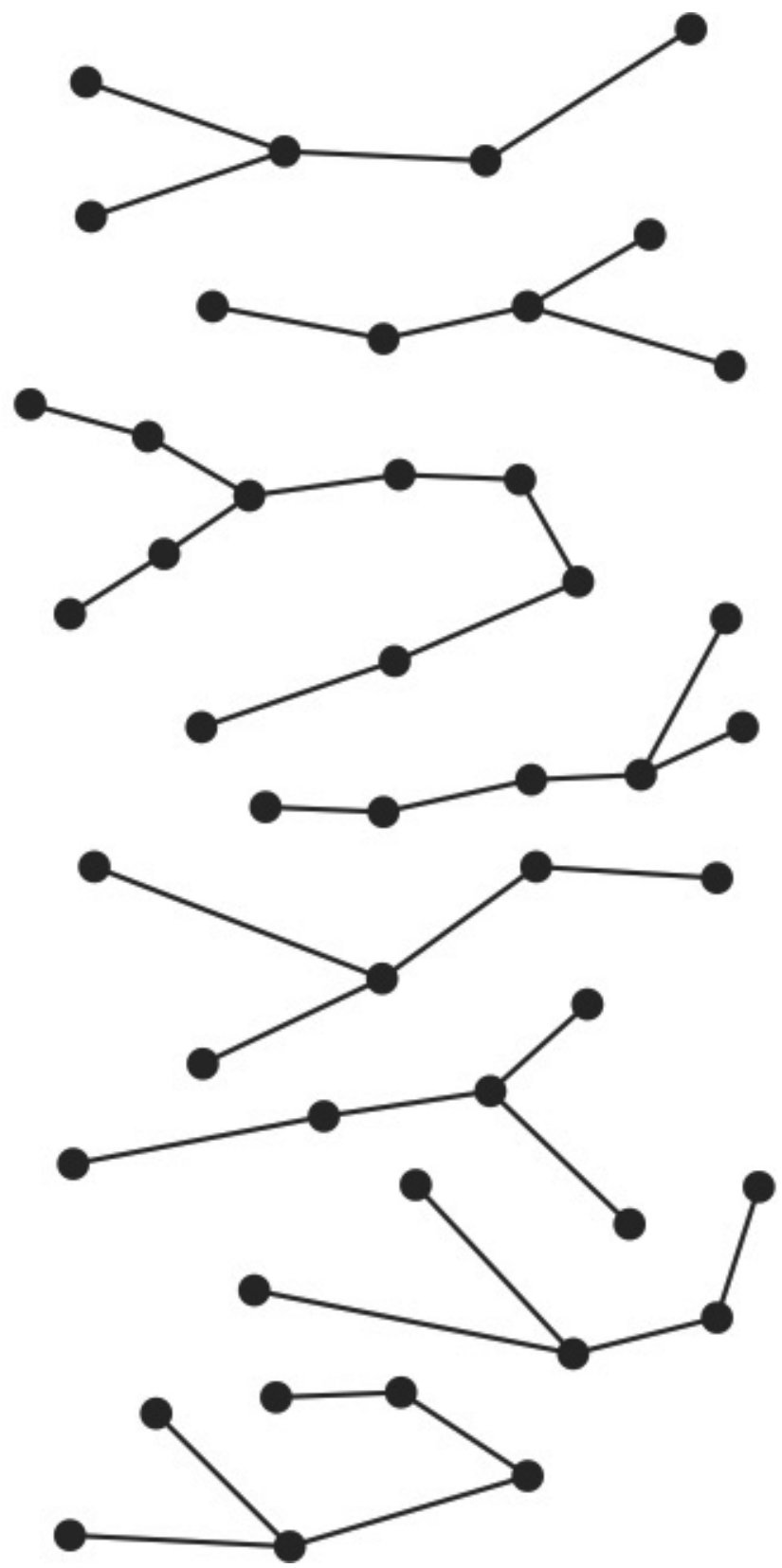

FIGURE 6.7 
